\title{
Mössbauer spectroscopy cell for in situ catalyst characterization and reaction kinetics studies at high pressures
}

\author{
W. M. Shen, J. A. Dumesic, a) and C. G. Hill, Jr. \\ Department of Chemical Engineering, University of Wisconsin, Madison, Wisconsin 53706 \\ (Received 26 September 1980; accepted for publication 11 February 1981)
}

\begin{abstract}
A stainless steel cell with beryllium windows has been used for carrying out in situ Mössbauer spectroscopy studies (with a vertical $\gamma$-ray beam) at pressures up to $6.8 \mathrm{MPa}$ and temperatures up to $773 \mathrm{~K}$. The downflow of gas through the powdered catalyst sample minimizes bulk gas phase concentration gradients in the cell above the catalyst layer, and this allows reaction kinetics measurements to be routinely analyzed. Incorporation of a prereactor and/or postreactor makes it possible to model longitudinal variations of catalyst states in a packed catalyst bed.
\end{abstract}

PACS numbers: $76.80 .+\mathrm{y}, 07.35 .+\mathrm{k}$

\section{INTRODUCTION}

The structure and properties of catalytic materials are sensitive to such environmental conditions as temperature, gas composition, and pressure. This places a premium on in situ catalyst characterization. When coupled with simultaneous studies of reaction kinetics, in situ spectroscopic measurements can lead to correlations between kinetic behavior (activity and selectivity) and such solid state properties of the active catalyst phase as its crystal structure and lattice parameters, surface and bulk composition, morphology and dispersion, and chemical bonding and valence states.

In recent years Mössbauer spectroscopy has proved to be an effective technique for the in situ investigation of heterogeneous catalysts. ${ }^{1-3}$ In principle, the Mössbauer parameters (i.e., recoil-free fraction, isomer shift, quadrupole splitting, and magnetic hyperfine field) can provide detailed information about the structure of the catalyst under a wide range of reaction conditions. For in situ Mössbauer spectroscopy studies, one needs simply a Mössbauer spectroscopy sample cell that incorporates the appropriate windows required for transmission of $\gamma$ rays through the cell, the mechanical strength necessary to maintain structural integrity of the cell at the elevated temperatures and pressures typical of industrial operating conditions (e.g., $700 \mathrm{~K}$ and 5 $\mathrm{MPa}$ ), and a geometry suitable for reaction kinetics measurements.

Several designs of Mössbauer spectroscopy cells for in situ catalyst characterization have been described elsewhere. ${ }^{2-6}$ However, these cells cannot be used at pressures significantly higher than atmospheric pressure. Furthermore, the geometries involved allow the reactant gas mixture to flow over, but not through, a thin layer of catalyst or a catalyst wafer. The existence of a bulk gas phase concentration gradient in the direction perpendicular to the catalyst layer or wafer is very probable for these configurations. In this respect, the present paper describes a simple Mössbauer spectroscopy cell that provides (i) the capability of operating at pressures up to $6.8 \mathrm{MPa}$ and temperatures up to $773 \mathrm{~K}$, and (ii) a flow arrangement which allows a reactant gas mixture to flow downwards through the catalyst bed at a rate which minimizes gas phase concentration gradients. In addition, this cell facilitates studies of different layers of catalyst in a packed bed reactor. In this application, the cell is used in tandem with a "prereactor" and/or a "postreactor." For gas handling and simultaneous kinetic data measurements, the cell is employed in a high pressure reactor system which has been described elswhere. ${ }^{\top}$

\section{APPARATUS}

\section{A. The high-pressure cell}

A schematic diagram of the high-pressure Mössbauer spectroscopy cell is shown in Fig. 1. The cell is designed to operate with a vertical $\gamma$-ray beam. The cell body is constructed of $2.54 \mathrm{~cm}$ o.d. $\times 2.06 \mathrm{~cm}$ i.d. 316 stainless steel tubing. The ends of this tubing were welded to ConFlat flanges (Varian \#954-5067). The use of type 316 stainless steel eliminates the formation of $\mathrm{Fe}(\mathrm{CO})_{5}$ and minimizes the formation of $\mathrm{Ni}(\mathrm{CO})_{4}$ at high carbon monoxide partial pressures. ${ }^{8}$ The upper portion of the cell was bored to create a seat for a quartz basket in which the catalyst was held. This basket was made of a $70-\mathrm{cm}$ length of quartz tube with an outer diameter which was slightly smaller than the inner diameter of the bored stainless steel tubing, but larger than the inner diameter of the original stainless steel tubing. Figure 2 is a photograph of this quartz basket (with the thermocouple used to measure the temperature of the catalyst bed, as discussed later). The upper $5.1 \mathrm{~cm}$ of this quartz tube had one quarter of its periphery cut out, so that it would not block the flow of gases into the cell. At the lower end of the basket a coarse screen was fashioned from two mutually perpendicular sets of two parallel quartz rods, 


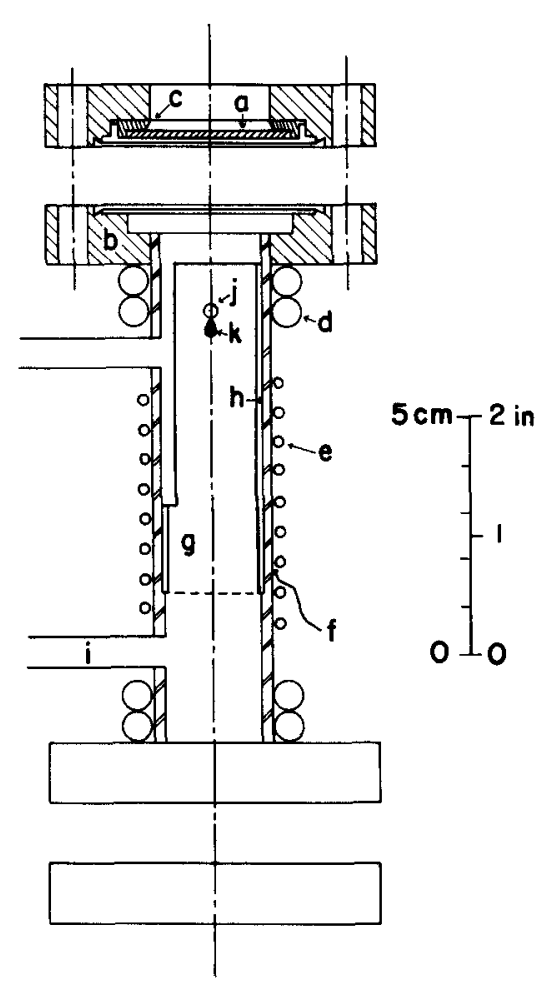

FIG. 1. The high pressure Mössbauer cell with copper gaskets and Kapton protection films omitted. (a) Beryllium window, (b) ConFlat flange, (c) stainless steel to aluminum transition ring, (d) Copper tubing for cooling water, (e) Nichrome heating element, (f) Thermocouple, (g) Quartz catalyst basket, (h) Stainless steel cell body $(2.54 \mathrm{~cm} \mathrm{o.d.)}$, (i) Stainless steel tubing $(0.64 \mathrm{~cm}$ o.d. $)$, (j) Holes to facilitate basket removal at the end of each experiment, (k) Quartz hooks for fixing the position of thermocouple.

fastened to one another and to the quartz tube. The diameter of these rods $(1-2 \mathrm{~mm})$ was kept small in order to maximize the open area for $\gamma$-ray transmission through the quartz screen. A thin layer of pressed quartz wool, upon which catalyst powder of interest can be evenly distributed, was then placed on the quartz screen. Two small holes in the wall of the upper portion of the basket facilitated its removal from the high pressure cell at the end of each experiment. A quartz hook was attached beneath each of these holes to fix the position of the thermocouple used to measure the temperature of the catalyst bed (see Fig. 2). Two pieces of $0.64 \mathrm{~cm}$ o.d. 316 stainless steel tubing were welded to the cell body to provide for entrance and exit of reactant gases. The gas enters the cell through the upper tube, and the reactor operates with downflow of gas through the catalyst sample. Heating of the cell is accomplished by passing electrical current through \#25 Nichrome wire, with an overall resistance of $15.5 \Omega$ at room temperature, wound around the cell in a manner such that no magnetic field was created in the cell during passage of current. This was done by folding the wire at its midpoint and wrapping the two halves around the cell in parallel with one another. An iron/constantan thermocouple was welded to the outer cell wall for cell temperature measurement and control. In addition, a flexible chromel/ constantan thermocouple was introduced into the cell through a tee (Swagelok) in the gas entrance tube, wound around the hooks on the quartz tube, and then placed in direct contact with the catalyst powder. The pressure seal for introduction of this thermocouple through a piece of $0.32 \mathrm{~cm}$ o.d. tubing into the tee in the gas entrance tube was made using a high strength epoxy (Devcon F). This thermocouple measures the temperature of the catalyst bed under reaction conditions.

Beryllium discs, mounted on ConFlat flanges, serve as $\gamma$-ray transparent windows when bolted onto the top and bottom of the Mössbauer spectroscopy cell. These Be discs (HIP-50) were supplied by Kawecki Berylco Industries, Inc. They were $3.48 \mathrm{~cm}$ in diameter and 0.23 $\mathrm{cm}$ thick. This thickness was chosen to provide high $\gamma$-ray transmission, yet allow high pressure operation. (The thickness was calculated using tabulated equations, ${ }^{9}$ mechanical properties of HIP-50, ${ }^{10}$ and a safety factor of 2.) Indeed, the upper limit on the pressure at which the cell can be operated is set by the strength of the beryllium windows. The strength of the windows depends not only on the type and thickness of the material used, but also on the method used for mounting the beryllium windows. Good mechanical strength was achieved using HIP-50 beryllium, electron beam welded by Electrofusion Co. to ConFlat flanges. An aluminum/stainless steel transition ring between the beryllium disc and the ConFlat flange is required by the welding process, and standard copper gaskets are used for sealing the ConFlat flanges to the body of the cell. It should be noted that HIP-50 beryllium contains $600 \mathrm{ppm}$ of iron impurity. The contribution of this iron to the Mössbauer spectrum will be discussed later.

Before sealing the Be window (with its associated

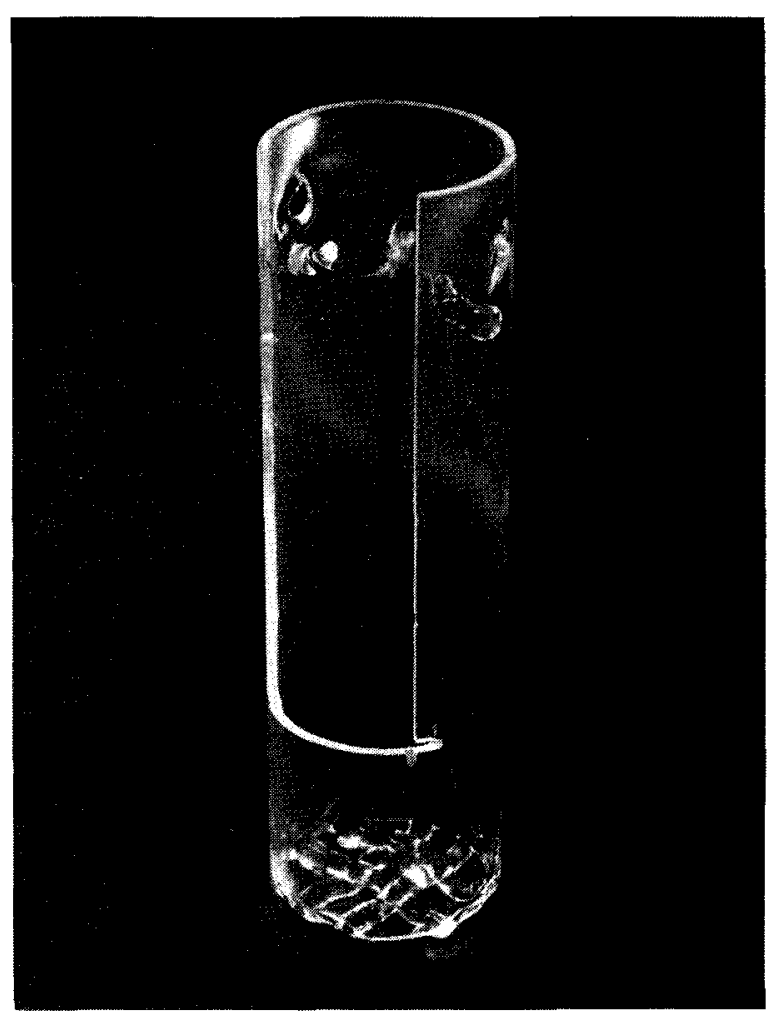

FIG. 2. Photograph of quartz catalyst basket. 
ConFlat fiange) to the Mössbauer spectroscopy cell, a thin (ca. $0.1 \mathrm{~mm}$ thick) Kapton film (DuPont $500 \mathrm{~F} 131$ ) was placed between the copper gasket and the ConFlat flange welded to the cell body. The two flanges were then bolted together. Once the cell is pressurized, the Kapton film is sealed against the copper gasket, thereby preventing any condensable component from reaching the beryllium window. This avoids the problems associated with cleaning the $\mathrm{Be}$ windows following studies of catalytic reactions involving species that may condense or deposit on the windows. Finally, the temperature of the Be windows can be regulated using two turns of water-cooled copper tubing at each end of the cell. Square copper tubing $(0.64 \mathrm{~cm}$ each side, $0.32 \mathrm{~cm}$ i.d. $)$, rather than round copper tubing, was used to provide larger contacting area between the copper cooling coil and the cell body. The tubings were mechanically wound around the ends of the cell.

\section{B. The prereactor and the postreactor}

A prereactor and a postreactor were mounted on the Mössbauer spectroscopy cell inlet and outlet, respectively. These two reactors are identical and are made of 316 stainless steel tubing, $1.27 \mathrm{~cm}$ o.d. and $7.62 \mathrm{~cm}$ in length. They were connected to the Mössbauer spectroscopy cell using Swagelok fittings. To keep the catalyst powder in place within each reactor, pieces of 200 mesh screen were placed between the ends of the tubing and the Swagelok fittings. An iron/constantan thermocouple, soldered to the tip of a $0.32-\mathrm{cm}$ o.d. thermocouple well, was placed at the center of the reactor through the reactor wall. The prereactor is located about $10 \mathrm{~cm}$ upstream of the Mössbauer spectroscopy cell, while the postreactor is located about $10 \mathrm{~cm}$ downstream. This arrangement allows the relative amounts of catalyst in the prereactor and postreactor to be varied, while keeping constant the total amount of catalyst in both reactors plus the Mössbauer spectroscopy cell. In this way, Mössbauer spectroscopy studies of the longitudinal variation of catalyst states in a packed catalyst bed are made possible.

The addition of these two reactors to the Mössbauer spectroscopy cell allows one to vary over a wide range the reactant space velocity (i.e., reactant volumetric flow rate divided by weight of catalyst bed) and the extent of reactant conversion (to products) through the entire reactor network. For example, the reactor network can be operated at the low conversions typical of laboratory studies or at the high conversions of interest to industry. In fact, this is done keeping an "optimal" amount of Mössbauer isotope (e.g., ${ }^{57} \mathrm{Fe}$ ) in the Mössbauer spectroscopy cell. Specifically, too much Mössbauer isotope in the cell results in broad spectral features that complicate data analysis. ${ }^{2}$

\section{PERFormance}

The ultimate pressure limit of the beryllium windows has not been studied, but the windows have passed static pressure tests at $6.8 \mathrm{MPa}$ and $773 \mathrm{~K}$ carried out at Electrofusion Co. Cooling water flowing through the cooling coils at the ends of the Mössbauer spectroscopy cell was effective in keeping the beryllium windows at temperatures below $353 \mathrm{~K}$, even when the cell body was maintained at a temperature as high as $656 \mathrm{~K}$. The thin layer of pressed quartz wool in the quartz catalyst basket is capable of holding catalyst powder in this downflow design. No powder was observed on the lower beryllium window after the experiments. The maximum temperature at which the cell can be operated is determined by the maximum electric current that the Nichrome wire winding can carry (ca. $4.5 \mathrm{~A}$ ). The cell has never been operated at its limit. However, it is known that the cell can be heated to $1038 \mathrm{~K}$ with a power input of $200 \mathrm{~W}$.

The high content of iron impurities in the beryllium windows $(600 \mathrm{ppm})$ gives rise to a doublet in the Mössbauer spectrum. The computer-fitted quadrupole splitting was $0.576 \mathrm{~mm} / \mathrm{s}$. It agrees with the published value of $0.58 \mathrm{~mm} / \mathrm{s}$ for an iron in beryllium solution. "The peak positions, widths, and dips were essentially constant in runs for which the temperature of the empty cell was varied from room temperature to $523 \mathrm{~K}$. Theoretically, such a background correction should require, for example, a second-order Doppler shift adjustment. However, as mentioned earlier, water cooling was used to keep the temperature of the beryllium windows lower than the cell temperature. The calculated change in isomer shift from room temperature (using the high temperature approximation ${ }^{11}$ ) is only $\mathrm{ca} .-0.040 \mathrm{~mm} / \mathrm{s}$ when the windows are $353 \mathrm{~K}$, the maximum temperature observed. The largest measured difference in isomer shifts among blank runs was $\mathrm{ca} .0 .010 \mathrm{~mm} / \mathrm{s}$. In short, in computer fitting in situ spectra of iron-containing catalysts at temperatures up to at least $523 \mathrm{~K}$, the contribution from iron impurities in the beryllium windows can be constrained to be the same as that observed during room temperature blank runs of the cell itself.

Mössbauer spectroscopy relies on the well-defined Doppler velocity of the radioactive source with respect to the stationary absorber (i.e., the catalyst in the cell). This makes the Mössbauer spectrum sensitive to any vibrations of the catalyst powder in the Mössbauer spectroscopy cell. To test for such effects, sponge iron powder was studied as a model catalyst in the reactor. In particular, $110 \mathrm{mg}$ of sponge iron powder (with granule sizes $5-32 \mu$ ) was evenly distributed on the layer of quartz wool in the quartz catalyst basket. Four Mössbauer spectra were then collected in hydrogen under various flow conditions. The spectra are shown in Fig. 3. The solid lines indicate computer-fitted absorption peaks. The experimental conditions and results are summarized in Table I. The superficial linear velocities were calculated on the basis of the cross-sectional area of the high pressure cell. Spectrum (a) was collected under static hydrogen pressure at room temperature. The line widths of this spectrum are used as standards for assessing the extent of catalyst vibration under various flow conditions. This is justified by the absence of both 

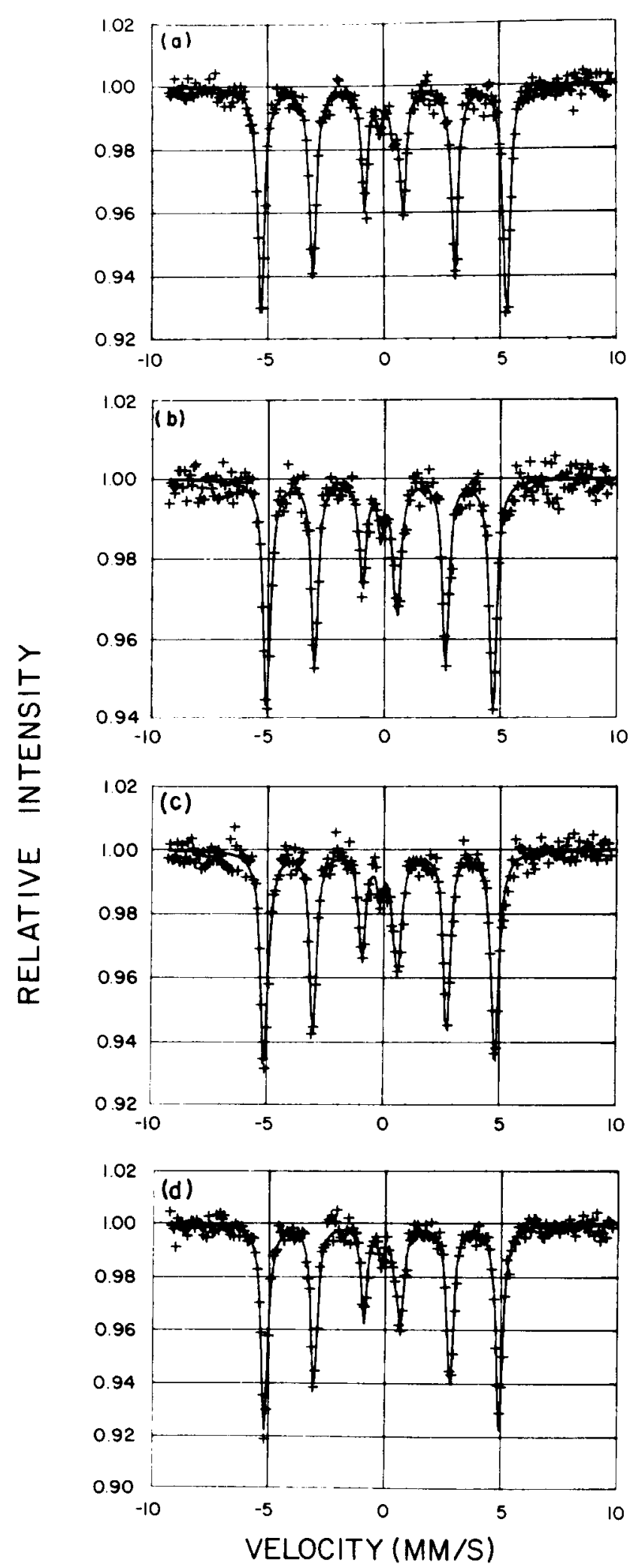

Fıg. 3. Mössbauer spectra of iron powder under various hydrogen flow conditions. The experimental conditions are summarized in Table I. The central doublet due to the iron impurities in the beryllium windows can be seen in spectrum (a). In other spectra, the peak with positive Doppler velocity superimposes on line 4 (counting from left to right) of the iron sextuplet. The solid lines are computer-fitted resonant absorption peaks.

gas flow through the thin catalyst layer and cooling water running through the cooling coils. The line widths of spectra (b)-(d) are comparable with (but a little broader than) those of spectrum (a). Thus, one may conclude that vibration of catalyst powder in this downflow arrangement is minimal for the range of flow rates considered.

For catalyst temperature measurement in this cell, it is essential to have a thermocouple in contact with the catalyst bed, as shown for example in Fig. 2. In particular, it has been observed in this cell that the cell-wall temperature (measured by the thermocouple welded to the outer cell wall) can be $40-50 \mathrm{~K}$ higher than the catalyst temperature (measured by the thermocouple in contact with the catalyst bed) when the catalyst is under high pressure (ca. $1000 \mathrm{kPa}$ ) Fischer-Tropsch synthesis conditions (ca. $520 \mathrm{~K}$ ). It has also been observed that the cell-wall temperature can be $50 \mathrm{~K}$ lower than the catalyst temperature when an exothermic reaction, e.g., methanation over a Ni catalyst, is carried out at high conversions. It should be noted that in addition to using a thermocouple in the catalyst bed, one can use the known temperature dependence of the isomer shift and/or the magnetic hyperfine field for well-defined materials (e.g., iron,,$^{12}$ magnetite,,$^{13}$ and copper ferrite $\left.{ }^{14}\right)$ to determine directly the temperature of the catalyst particles. This method is potentially of value in studies of exothermic reactions where small particles of catalytic material may be at temperatures higher than the powdered support whose temperature is measured by the thermocouple immersed in the catalyst bed. The disadvantage of this method, however, is that the chemical state of the Mössbauer isotope in the catalyst under reaction conditions is not known a priori. In general, a temperature reading from a thermocouple in contact with the catalyst bed, in combination with the known temperature dependence of Mössbauer parameters, probably gives the most reliable means of temperature measurement. To conclude this discussion of temperature measurement, it is noted that the Mössbauer spectra of Fig. 3 indicate that significant radial temperature gradients were not present in the layer of catalyst in the quartz basket. A distribution of magnetic hyperfine fields resulting from a nonuniform temperature of the catalyst bed would give rise to a broadening of the Mössbauer spectrum, and this was not observed experimentally (see Fig. 3 and Table I). Specifically, it can be calculated that the slightly broader lines of spectrum (c), compared to spectrum

TABLE 1. Results of test runs using sponge iron powder.

\begin{tabular}{cccccc}
\hline \hline Spectrum & $\begin{array}{c}\text { Pressure } \\
(\mathrm{kPa})\end{array}$ & $\begin{array}{c}\mathrm{H}_{2} \text { flow } \\
\text { rate } \\
(\text { liter } \\
\mathrm{min})\end{array}$ & $\begin{array}{c}\text { Linear } \\
\text { velocity } \\
(\mathrm{cm} / \mathrm{s})\end{array}$ & $\begin{array}{c}\text { Tempera- } \\
\text { ture }^{2} \\
(\mathrm{~K})\end{array}$ & $\begin{array}{c}\text { Line } \\
\text { width }^{3} \\
(\mathrm{~mm} / \mathrm{s})\end{array}$ \\
\hline $\mathrm{a}$ & 303 & 0 & 0 & 298 & 0.347 \\
$\mathrm{~b}$ & 310 & 0.22 & 0.83 & 656 & 0.374 \\
$\mathrm{c}$ & 1034 & 1.00 & 1.15 & 616 & 0.399 \\
$\mathrm{~d}$ & 345 & 1.50 & 5.92 & 530 & 0.354 \\
\hline
\end{tabular}

${ }^{1}$ Referred to standard conditions, i.e., $273 \mathrm{~K}$ and atmospheric pressure.

"Measured by the thermocouple welded to the outer cell wall.

"Linewidth of the outermost resonant peaks. 


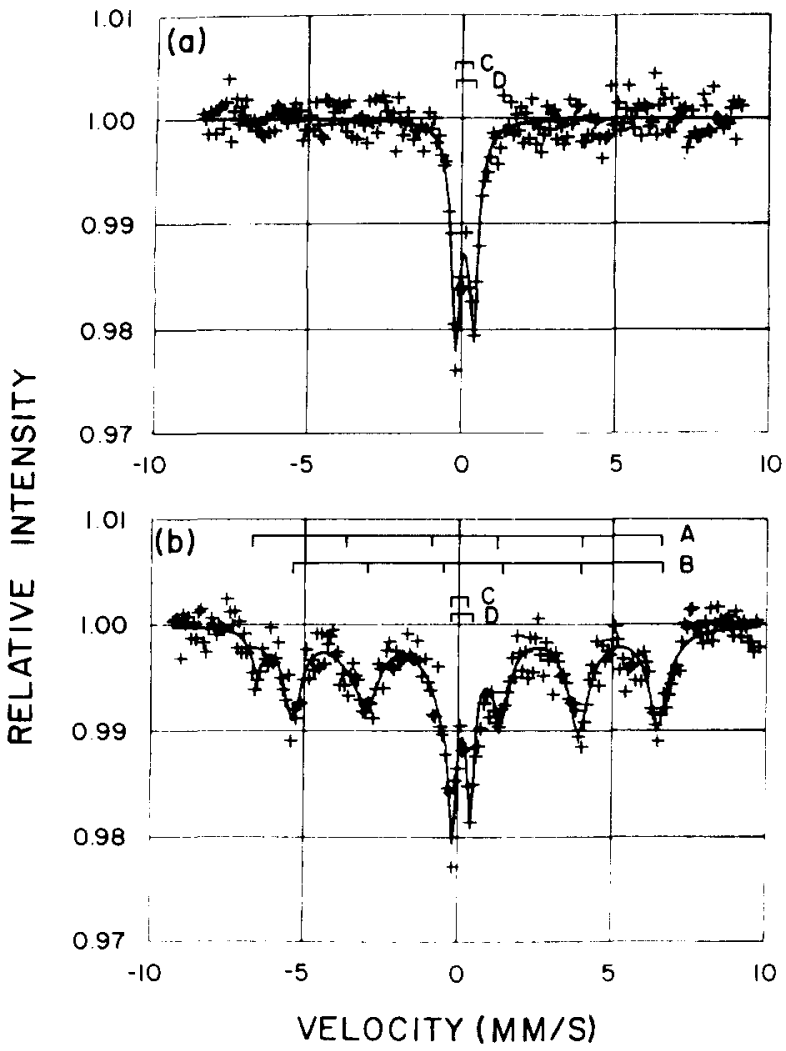

FIG. 4. In situ Mössbauer spectra of an iron-containing FischerTropsch catalyst. (a) The top layer of the iron catalyst bed. (b) The bottom layer of the iron catalyst bed. The spectra were collected under the following operating conditions: $T=570 \mathrm{~K}, P=994 \mathrm{kPa}, \mathrm{H}_{2}$ flow rate $=20 \mathrm{~cm}^{3} / \mathrm{min}$, and $\mathrm{H}_{2} / \mathrm{CO}$ ratio $=1.54$. These operating conditions resulted in $86.5 \% \mathrm{CO}$ conversion, and $5.7 \%$ and $36.8 \%$ selectivities toward $\mathrm{CH}_{4}$ and $\mathrm{CO}_{2}$, respectively. The solid lines are computerfitted absorption peaks. The computer-fitted peak positions are shown by means of stick diagrams $\mathrm{C}$ and $\mathrm{D}$, corresponding to absorption peaks from iron carbide and iron impurities in the beryllium windows, respectively. In spectrum (b), A and B designate the tetrahedral and the octahedral sites in a close-packed oxide lattice, respectively.

(a) indicate a radial temperature gradient of at most $10 \mathrm{~K}$ for the conditions reported in Table $I$.

Figure 4 shows in situ Mössbauer spectra of a promoted iron catalyst (Harshaw 689A-2-2-6G powder) under high pressure Fischer-Tropsch synthesis conditions. Spectrum (a) was collected from $0.1 \mathrm{~g}$ of catalyst in the Mössbauer spectroscopy cell, while spectrum (b) was obtained from $0.1 \mathrm{~g}$ of catalyst in the cell with $6.8 \mathrm{~g}$ of catalyst in the prereactor. For these two spectra, the samples in the Mössbauer spectroscopy cell thus correspond to the top and the bottom portion of a $6.9-\mathrm{g}$ catalyst bed, respectively. The difference in the catalyst states between the top layer and the bottom layer of this iron catalyst bed is easily seen. The catalyst state of the top layer of this promoted iron catalyst bed can be identified as a $\chi$-carbide phase..$^{15}$ The bottom layer of this promoted iron catalyst bed consists of a mixture of magnetite and $\chi$-carbide. In other experiments the composition of the bottom layer of the iron catalyst bed was found to depend on the extent of $\mathrm{CO}$ conversion. These results will be discussed in detail elsewhere. ${ }^{15}$

The capability of this high pressure Mössbauer spectroscopy cell, with pre- and postreactors, for kinetics studies has been established at both industrially important high conversion levels and research-oriented low conversion levels. As an example of the former application, the data listed in the caption of Fig. 4 agree very well with published results from flow reactors under similar reaction conditions. ${ }^{16}$ As an example of low-conversion (ca. 5\%) data, the methanation kinetics observed over a $\mathrm{Ni}$ catalyst in a tubular, high pressure reactor ${ }^{7}$ have also been reproduced in the high pressure Mössbauer cell (with the pre- and postreactors empty).

\section{ACKNOWLEDGMENTS}

Financial support by the Department of Energy is gratefully acknowledged.

a) Camille and Henry Dreyfus Foundation Teacher Scholar, to whom correspondence should be addressed.

' W. N. Delgass and M. Boudart, Catal. Rev. 2, 129 (1968).

2 J. A. Dumesic and H. Topsøe, Adv. Catal. 26, 121 (1976).

H. Topsøe, J. A. Dumesic, and S. Mørup, in Application of Mössbauer Spectroscopy, edited by R. L. Cohen (Academic, New York, 1980), Vol. 2, p. 55.

${ }^{4}$ P. R. Gray and F. E. Farha, in Mössbauer Effect Methodology, edited by I. J. Gruverman and C. W. Seidel (Plenum, New York, 1976), Vol. 10, p. 47.

5 J. A. Dumesic, Y. V. Maksimov, and I. P. Suzdalev, in Mössbauer Effect Methodology, edited by I. J. Gruverman and C. W. Seidel (Plenum, New York, 1976), Vol. 10, p. 31.

"W. N. Delgass, L. Y. Chen, and G. Vogel, Rev. Sci. Instrum. 47, 968 (1976)

' W. M. Shen, J. A. Dumesic, and C. G. Hill, Jr., J. Catal. (to be published).

${ }^{8}$ H. Inouye and J. H. DeVan, J. Mater. Energy Syst. 1, 52 (1979).

" W. Griffel, Handbook of Formulas for Stress and Strain (F. Ungar, New York, 1966), Chap. 5.

${ }^{10}$ Product data supplied by Kawecki Berylco Industries, Inc. File number 302 19-PD1, 1977.

${ }^{11}$ N. N. Greenwood and T. C. Gibb, Mössbauer Spectroscopy (Chapman \& Hall, London, 1971)

12 R. S. Preston, S. S. Hanna, and J. Herberle, Phys. Rev. 128, 2207 (1962)

${ }_{1: 3}$ H. Topsøe and M. Boudart, J. Catal. 31, 346 (1973).

B. J. Evans and S. S. Hafner, J. Phys. Chem. Solids 29, 1573 (1968).

${ }_{15}$ W. M. Shen, J. A. Dumesic, C. G. Hill, Jr., and R. J. Madon, (to be published).

${ }^{16}$ R. J. Madon, E. R. Bucker, and W. F. Taylor, Final Report, Department of Energy, Contract E(46-1)-8008, July, 1977. 